\title{
Focus on the future: episodic future thinking reduces discount rate and snacking
}

Citation for published version (APA):

Dassen, F. C. M., Jansen, A., Nederkoorn, C., \& Houben, K. (2016). Focus on the future: episodic future thinking reduces discount rate and snacking. Appetite, 96, 327-332.

https://doi.org/10.1016/j.appet.2015.09.032

Document status and date:

Published: 01/01/2016

DOI:

10.1016/j.appet.2015.09.032

Document Version:

Publisher's PDF, also known as Version of record

\section{Please check the document version of this publication:}

- A submitted manuscript is the version of the article upon submission and before peer-review. There can be important differences between the submitted version and the official published version of record.

People interested in the research are advised to contact the author for the final version of the publication, or visit the DOI to the publisher's website.

- The final author version and the galley proof are versions of the publication after peer review.

- The final published version features the final layout of the paper including the volume, issue and page numbers.

Link to publication

\footnotetext{
General rights rights.

- You may freely distribute the URL identifying the publication in the public portal. please follow below link for the End User Agreement:

www.umlib.nl/taverne-license

Take down policy

If you believe that this document breaches copyright please contact us at:

repository@maastrichtuniversity.nl

providing details and we will investigate your claim.
}

Copyright and moral rights for the publications made accessible in the public portal are retained by the authors and/or other copyright owners and it is a condition of accessing publications that users recognise and abide by the legal requirements associated with these

- Users may download and print one copy of any publication from the public portal for the purpose of private study or research.

- You may not further distribute the material or use it for any profit-making activity or commercial gain

If the publication is distributed under the terms of Article $25 \mathrm{fa}$ of the Dutch Copyright Act, indicated by the "Taverne" license above, 


\title{
Focus on the future: Episodic future thinking reduces discount rate and snacking
}

\author{
Fania C.M. Dassen*, Anita Jansen, Chantal Nederkoorn, Katrijn Houben \\ Department of Clinical Psychological Science, Maastricht University, Maastricht, The Netherlands
}

\section{A R T I C L E I N F O}

\section{Article history:}

Received 1 July 2015

Received in revised form

21 September 2015

Accepted 25 September 2015

Available online 30 September 2015

\section{Keywords:}

Eating behavior

Episodic future thinking

Time orientation

Delay discounting

Reducing impulsivity

\begin{abstract}
A B S T R A C T
Obesity seems related to a preference for immediate gratification. By changing this focus on short term benefits to a more future-oriented outlook, delay discounting (impulsive decision making) can be changed by a manipulation of episodic future thinking (EFT). EFT comprises a vivid mental simulation of general future experiences. EFT may also affect consumption of unhealthy foods, which can be seen as a choice for immediate gratification. Recent research shows that future orientation should be tailored to the behavior at outcome. We therefore hypothesize that the effectiveness of EFT on food intake could be enhanced by making the content food-related. We conducted a 2 (future vs past thinking) by 2 (food vs non-food related thoughts) between-subject design experiment in female undergraduates $(N=94)$, to compare the efficacy of EFT versus the recalling of episodic past events in reducing discount rate and caloric intake. Content of imagery was either unrestricted or food-related. Participants engaged in EFT or control episodic imagery while snacks were offered to freely consume, and next the Monetary Choice Questionnaire was completed as a measure of delay discounting, while again being engaged in EFT or control imagery. Both types of EFT reduced delay discounting, however, only food-related EFT lead to more restricted caloric consumption. Thus, we found evidence that EFT reduced discount rate during decision making. However, in order to restrict caloric intake, EFT should entail food-related imagery. As discount rate and caloric intake were not related in the current sample, the underlying mechanism remains to be discovered. Results however suggest that EFT is a promising technique to resist immediate gratification.
\end{abstract}

๑) 2015 Elsevier Ltd. All rights reserved.

\section{Introduction}

In the last decades, people became increasingly heavier and physically less fit, and the prevalence of obesity has increased worldwide (Finucane et al., 2011; Flegal, Carroll, Kit, \& Ogden, 2012). When a person's energy intake is greater than one's energy consumption, weight gain will occur (Hill, Melanson, \& Wyatt, 2000). Why is it so difficult for some to resist the temptation of palatable food? The taste of high sugar and high fat foods is highly enjoyable (Drewnowski \& Greenwood, 1983) and eating high caloric foods is very rewarding at the time of consumption: the immediate contingencies are positive (Volkow, Wang, \& Baler, 2011). When choosing what to eat, we have to weigh immediate pleasures vs. long-term health implications (e.g. healthy body

\footnotetext{
* Corresponding author. Department of Clinical Psychological Science, Maastricht University, P.O. Box 616, 6200 MD Maastricht, The Netherlands.

E-mail address: f.dassen@maastrichtuniversity.nl (F.C.M. Dassen).
}

weight and reduction of health risks) (Hall \& Fong, 2007). When one is mainly focused on immediate pleasures, this could lead to palatable, though unhealthy, food choices. Studies on preferences for immediate reward frequently used a delay discounting task, in which individuals have to choose between a more valuable reward after a period of delay and a less valuable reward which is directly available (e.g., Bickel \& Marsch, 2001). Dual-system models of decision-making (e.g. Bechara, 2005; Bickel et al., 2007) posit that delay discounting reflects the relative balance in activation between two competing neurobiological systems. The appetitive, impulsive system values immediate reinforcers, whereas the inhibitory, executive system is needed for the inhibition of the impulsive system to maximize long-term gains (Bickel et al., 2007). Someone who chooses relatively more often for the immediate smaller reward is thus considered to be more impulsive, whereas someone who is more willing to wait for a bigger reward, places more emphasis on benefits in the future (Bickel et al., 2007). Research has shown that obese individuals are more affected by 
this period of delay than subjects with a healthy weight, and a higher discount rate (i.e., less willingness to wait for future benefits) is related to a higher Body Mass Index (BMI) (Epstein et al., 2014; Jarmolowicz et al., 2014; Weller, Cook III, Avsar, \& Cox, 2008). A higher discount rate is also predictive of higher calorie intake in obese women (Appelhans et al., 2012) and children who are having more difficulty delaying reward, lost less weight during a weight loss intervention (Best et al., 2012). Changing this concern with immediate reward into a more future-oriented outlook could therefore be useful in order to promote the choice of healthy foods and thereby facilitate a healthy weight.

Episodic future thinking (EFT) is one strategy to shift one's preference from immediate gratification to delayed rewards (Peters \& Büchel, 2010). EFT refers to the possibility of humans to project themselves forward in time and to pre-experience future events (Atance \& O'Neill, 2001). Simulation of a future event is a relatively unconstrained task that places many demands on executive functions (Schacter, Addis, \& Buckner, 2008) and integrating episodic future images in choice behavior increases activation in the executive system (Peters \& Büchel, 2010). This increased activation of the executive system could be resulting in an increased choice of delayed rewards (Koffarnus, Jarmolowicz, Mueller, \& Bickel, 2013). It is suggested that this capacity for EFT gives people the ability to counteract their natural disposition to short-term decision making and to make restraint choices with long-term benefits. EFT thus has adaptive utility resulting in higher evolutionary fitness (Boyer, 2008). Thoughts about the future are frequently used in daily life to plan actions and make decisions (D'Argembeau, Renaud, \& Van der Linden, 2011). EFT possibly heightens connectedness and reduces perceived distance between the future and now (Koffarnus et al., 2013) and it seems to help in assessing the value of delayed rewards (Bar, 2010). Interestingly, Benoit, Gilbert, and Burgess (2011) showed the greatest decrease in discount rate after EFT for those scoring low on the Consideration of Future Consequences Scale (Strathman, Gleicher, Boninger, \& Edwards, 1994), a measure of time orientation which entails the extent to which people consider immediate versus future consequences of potential behaviors. Thus, these results indicate that a stimulation of EFT is the most beneficial to those who in general do not take future outcomes in account.

Engaging in EFT during decision making may help individuals to delay gratification in food choice (Daniel, Stanton, \& Epstein, 2013a). Weight management is in general considered more important than eating snacks, until snacks are available and negative consequences are discounted (Boyer, 2008). In earlier research, EFT reduced caloric intake in obese women (Daniel, Stanton, \& Epstein, 2013b) and overweight children (Daniel, Said, Stanton, \& Epstein, 2015). These results suggest that EFT could indeed be a useful technique to endorse long term consequences and thereby control impulsive eating. It is important to note that Daniel and colleagues (Daniel et al., 2015, 2013b) found effects of EFT on eating behavior even though the EFT manipulation was unrelated to eating. Specifically, participants were encouraged to imagine vivid positive future events, whereby the content of imagery was not restricted. It thus seems that the imagined future events during EFT do not necessarily have to be related to the discounting task or to eating episodes: Considering general future events was enough to lead individuals into better eating-related choices in the present.

However, there is reason to believe that future orientation should be tailored to the behavior of interest. Someone can be more future oriented in one aspect of his behavior, but not in another (van Beek, Antonides, \& Handgraaf, 2013). Earlier research has shown that only a food-specific measure of time orientation was related to healthy eating patterns (Dassen, Houben, \& Jansen, 2015;
Hall, Fong, \& Cheng, 2012; van Beek et al., 2013): unhealthy eaters were focused on immediate benefits only with respect to food and health, whereas healthy eaters took future health-related consequences of their eating behavior into account (Dassen et al., 2015). These results suggest that the effectiveness of EFT could be enhanced by making the content food-related.

The goal of the current study is therefore to examine whether food-related EFT is more effective in promoting healthy dietary choices compared to general EFT. Participants were instructed to think vividly about the future or about past events and whether the thoughts were general or food-related in a $2 \times 2$ between subjects design. Following the episodic thought manipulation, we assessed discount rate and caloric intake. It was expected that the EFT conditions would show a reduction in both delay discounting and food intake relative to the control conditions. As a reduction in discount rate is suggested to be the underlying mechanism leading to a more restricted intake, we hypothesized that the effect of EFT on food intake is mediated by discount rate. In addition, it was hypothesized that food-related future imagination would be more effective in reducing caloric intake than general EFT.

\section{Methods}

\subsection{Participants}

Ninety-five female undergraduates of Maastricht University between the ages of 18-30 were recruited using advertisements for a study about the effects of deprivation on visualization. One participant was considered an outlier on the dependent variable (caloric intake $>3 \mathrm{SD}$ ) and therefore excluded from all analyses. Therefore, our final sample consisted of 94 participants.

\subsection{Procedure}

Participants were asked to refrain from consuming anything except for water for $2 \mathrm{hr}$ before participation. All appointments were scheduled between $11 \mathrm{am}$ and $6 \mathrm{pm}$. At arrival, participants signed the informed consent, completed demographical data, rated their current hunger, reported the time since their last meal and completed some filler-questionnaires. Next a "break" was introduced, in which snacks and water were provided to freely consume while the manipulation, presented as a writing assignment (either episodic future thinking or control; see description of manipulation below) had to be completed. After fifteen minutes, the experimenter came back and removed the food. When the participant did not finish yet, a maximum of 5 extra minutes to work on the assignment was provided (15 participants; $16 \%$ ), while the experimenter waited in the room. Everyone was finished after this extra time. Next, a computerized questionnaire to assess discount rate was completed. Subsequently, participants rated on a 7-point Likert scale how much they thought about and how vividly they imagined the events while completing the questionnaire. Next, the Consideration of Future Consequences scale - food version and Restraint Scale were completed. At the end of the study, participants' weight and length were measured, and they were fully debriefed. Completion took about $50 \mathrm{~min}$, and participants received one course credit or a voucher of $€ 7.50$ as a reward. The study was approved by the ethical committee of the Faculty of Psychology and Neuroscience of Maastricht University.

\section{Materials and measures}

\subsection{Manipulations}

Participants wrote about either events planned in the future 
(Episodic Future Thinking: EFT) or about past events as control (Episodic Past Thinking: EPT). Participants either had to come up with unrestricted or food-related events, depending on the condition they were allocated to. Participants received the following instructions (instructions for the conditions who wrote about past events are shown between parentheses):

"We want to ask you to imagine events that realistically could happen or that you have already planned in the future (in a week, two weeks, a month, six months) [recall events that have taken place recently (one day ago, two days ago, a week ago, a month ago)]. This may for example be a getaway or something study-related; Think of something that applies to you. Experience this event already in mind [Re-experience this event in mind]. Consider as many details of this event as possible (what do [did] you do, where are [were] you, who are [were] with you, accompanying feelings). These images will be used in the next exercise. Describe the situation below."

For the food-related EFT and EPT condition, it was added to the instruction that the events had to be food-related. As an example it was stated that this event could for instance be a dinner with friends or cooking an elaborate meal. Participants were also asked to consider how healthy the described food-related event is/was. Next, the participants rated every image on a 7-point Likert scale ( $1=$ not at all; $7=$ very much) on realism, details, vividness, positivity, difficulty to imagine, and how future-oriented the event was.

\subsection{Caloric intake}

Participants were provided with a bowl of chocolate chip cookies $( \pm 110 \mathrm{~g} ; 497 \mathrm{kcal} / 100 \mathrm{~g})$, a bowl of M\&M's $( \pm 200 \mathrm{~g}$; $485 \mathrm{kcal} / 100 \mathrm{~g})$, a bowl of syrup waffles ( $\pm 160 \mathrm{~g} ; 457 \mathrm{kcal} / 100 \mathrm{~g}$ ) and a bottle of water. Participants were told that for study purposes it was no longer needed for them to be deprived of food, and since they had not eaten for at least two hours, some snacks and water were now provided to freely consume, while they were preparing at ease for the next assignment. They were told they could eat as much or as little as they wanted. Participants were not aware of the fact that the food was weighed before and afterwards and that caloric intake was calculated.

\subsection{Monetary Choice Questionnaire}

In order to assess the ability to delay gratification, participants completed a computerized version of the Monetary Choice Questionnaire (Kirby, Petry, \& Bickel, 1999). This questionnaire consists of 27 questions, asking the respondent to choose either a smaller, immediate monetary reward or a larger, delayed monetary reward. An example of a question is "Would you prefer $€ 14$ today, or $€ 25$ in 19 days?" The timeframes of the future events approximated the time delays specified on the MCQ (7-186 days), based on time intervals specified by Lin and Epstein (2014). Participants received the following instructions regarding the EFT or control-EPT manipulation:

"This questionnaire consists of each a visualization task, where you have to imagine the events you just wrote about and subsequently a choice where you are asked to choose between an immediate reward and a higher reward you will only receive after a certain number of days. You will be asked which of the two rewards you prefer. The rewards include a certain amount of money. You will not really receive the amount of money you choose, but we want to ask you to make your decisions as if you actually would receive the money. Please choose the option that you would prefer to receive, and not what you think we want you to choose. They are a total of 27 choices. You do not have to base your choice upon the imagined event; you have just have to vividly imagine that this event is really happening, and next you can choose your preferred reward."

The geometric mean of the k-value (the degree of discounting) was calculated afterwards by use of an automated scoring spreadsheet made available online by Kaplan, Lemley, Reed, and Jarmolowicz (2014). See Kirby (2009) for more details about estimating the k-value. To normalize the distribution of scores, a natural-log transformation of $\mathrm{k}$ was used for all statistical analyses.

\subsection{Restraint Scale}

In order to discover the extent to which participants try to restrain or control their food intake, the Restraint Scale (RS; Herman \& Polivy, 1980), which assesses weight concerns, weight fluctuations and self-reported attempts to diet, was used in this study. The RS is a self-report questionnaire consisting of 10-items, with possible scores ranging from 0 to 35 . Higher scores are indicative of an increased intention to restrict food intake.

\subsection{Consideration of Future Consequences scale - food version}

In order to measure time perspective regarding eating behavior and health, participants completed the CFC-food (van Beek et al., 2013), an adapted version of the 14-item Consideration of Future Consequences Scale (CFC; Joireman, Shaffer, Balliet, \& Strathman, 2012). The CFC-food consists of two subscales: CFC-immediate and CFC-future. An example of an item of the Immediate-subscale is "I only choose my food to satisfy immediate needs, figuring the future will take care of itself." An example question for the Futuresubscale is "I consider how my health might be in the future, and try to influence my health with my day to day eating behavior." Participants indicated their agreement with the statements on a 7point Likert scale, ranging from $1=$ "totally disagree" to 7 = "totally agree."

\subsection{Body Mass Index}

The height and weight of each participant was measured to calculate the Body Mass Index (BMI; $\mathrm{kg} / \mathrm{m}^{2}$ ).

\subsection{Hunger and taste rating}

Participants were asked to indicate their current hunger at the beginning of the study. Participants were also asked to indicate how much they liked the offered snacks after removal of the bowls. Responses for hunger and taste rating were given on a $100 \mathrm{~mm}$ VAS-scale ranging from "not at all" to "very much".

\subsection{Analyses}

Participants were randomly assigned to EFT $(n=23)$, foodrelated EFT $(n=24)$, EPT $(n=24)$ or food-related EPT $(n=23)$. First, group differences in the ratings of the images, restraint and BMI were explored. In case of group differences, these variables were included as a covariate on all subsequent analyses. As a manipulation check, we expected EFT images to be rated as more future-oriented than EPT images. Next, two two-way between subjects ANOVA were conducted with manipulation (EPT or EFT) and content (general or food-related images) as factors, and either 
discount rate or caloric intake as dependent variable. For the analysis on caloric intake, current hunger and taste rating of the snacks were included as covariates.

\section{Results}

\subsection{Manipulation check}

Mean age of participants was 20.45 years $(S D=1.97$, range $18-29$ ) and mean BMI was 22.43 ( $S D=2.75$, range 17.74-31.78). The conditions did not differ on age, scores on the Restraint Scale or on calculated BMI (all p > 0.31; see Table 1 ). Hunger ratings were on average intermediate $(M=53.30, S D=24.20)$ and did not differ between conditions (see Table 1 ). Taste ratings of the offered snacks were on average moderately high $(M=65.98, S D=19.71)$. Participants who engaged in EPT $(M=70.10, S D=17.66)$ rated the snacks as more palatable than those who engaged in EFT $(M=61.87$, $S D=20.95), F(1,90)=4.20, p<.05, \eta^{2} p=0.05$. For CFC-food, groups did not differ on the CFC-immediate subscale (all $p>0.67$; see Table 1). For the future subscale, a significant difference for content occurred, $F(1,90)=5.05, p<.05, \eta_{p}^{2}=0.05$, indicating that food-related groups had higher scores on the CFCfuture subscale $(M=31.95, S D=4.85)$ than general groups $(M=29.21, S D=6.72)$.

All generated images were evaluated as reasonably realistic, detailed, vivid, easy to imagine and positive (see Table 2). No group differences on realism, details or difficulty of generating the images were found (all $p>0.24$; see Table 2). Food-related images $(M=5.97, S D=0.68)$ were on average evaluated as more positive than general images $(M=5.40, S D=0.92), F(1,90)=11.25, p<.01$, $\eta^{2}{ }^{2}=.11$, and, although not statistically significant, as slightly more vivid $(M=5.54, S D=0.61)$ than general images $(M=5.30$ $S D=0.75), F(1,90)=2.86, p=0.09, \eta^{2} p=.03 .{ }^{1}$ Regarding the extent to which events were rated as future-oriented, a main effect of the future manipulation was found, $F(1,90)=98.70, p<0.001$, $\eta^{2}{ }^{2}=0.52$, indicating that EFT groups $(M=5.23, S D=1.04)$ thought more about the future than the EPT groups $(M=2.81, S D=1.31)$. Thus, the EFT manipulation was successful in activating future images.

\subsection{Discount rate}

Groups did not differ on the vividness or amount of time spent on considering the events while they completed the MCQ (all $p>0.12$ ). In Fig. 1, results of the two-way between subjects ANOVA for delay discounting are presented. ${ }^{1}$ The interaction effect between manipulation and content was not significant $F(1,90)=0.01$, $p=0.94, \eta_{p}^{2}=.00$. There was a statistically significant main effect for the future manipulation, $F(1,90)=5.66, p=0.02, \eta^{2} p=.06$, which indicates that EFT (general: $M=-5.63, S D=1.33$; foodrelated: $M=-5.61, S D=1.46$ ) reduced discounting of the future relative to EPT (general: $M=-5.03, S D=1.03$; food-related: $M=-4.97, S D=1.21)$. The main effect of content, $F(1$, $90)=0.02, p=.89, \eta^{2}=.00$, was not significant, which indicates that results were not different for general or food-related images.

\subsection{Caloric intake}

Participants on average consumed 208.63 calories $(S D=160.56$,

\footnotetext{
${ }^{1}$ We also conducted all analyses with positivity and vividness included as a covariate (data not shown). However, as this did not change the pattern of outcomes, results are reported for the analyses without positivity and vividness included as a covariate.
}

Range 0-616.76). Discount rate and caloric intake were not correlated $(r=-0.03, p=0.76)$. Within groups, discount rate and caloric intake were also not related (all $p>0.47$ ). Results of the two-way between-groups analysis of covariance with manipulation and content as factors, and hunger and taste ratings included as covariates are presented in Fig. 2. ${ }^{1}$ Content of imagery was either general or food-related. Hunger, $F(1,88)=18.11, p<0.001, \eta^{2} p=.17$ and taste $F(1,88),=12.54, p=<0.01, \eta^{2} p=.13$, significantly predicted caloric intake. No main effect of manipulation, $F$ (1, $88)=2.58, p=.11, \eta^{2} p=0.03$ or content, $F(1,88)=0.09, p=.77$, $\eta^{2} p=0.00$, occurred. The interaction between manipulation and content was significant, $F(1,88)=5.01, p=.03, \eta^{2} p=0.05$. Post hoc analyses performed separately for general versus food-related content revealed that food-specific EFT (EMM $=164.46$, $S E=29.85)$ reduced caloric intake relative to food-related EPT $(E M M=273.79, S E=30.95), F(1,43)=5.97, p=.02, \eta_{p}^{2}=0.12$. For general content, in contrast, caloric intake did not differ between $\mathrm{EPT}(E M M=190.86, S E=26.78)$ and $\mathrm{EFT}(E M M=208.10$, $S E=27.37), F(1,43)=0.20, p=.66, \eta_{p}^{2}=0.01$.

\section{Discussion}

The aim of the current study was to test whether discount rate and caloric intake could be altered by a manipulation of episodic future thinking, by shifting concern with immediate gratification to a more future-oriented outlook. As only food-specific measures of time orientation are related to healthy eating patterns, the current study explored whether the effects of EFT on food intake could be enhanced by making the content of imagery food-related. Delay discounting was indeed reduced by EFT. This effect was not determined by content: Both general and food-related EFT led to less discounting of the future compared to control groups who relived recent episodic past events. Further, in line with our hypothesis, results showed that only food-related EFT, but not general EFT, reduced food intake.

Thus, EFT during decision making resulted in less frequent choices of immediate reward, in accordance with earlier research (Benoit et al., 2011; Daniel et al., 2015, 2013a, 2013b; Lin \& Epstein, 2014; Peters \& Büchel, 2010). As unhealthy eaters are mainly present-minded for food and not in general (Dassen et al., 2015), only food-specific future thinking resulted in more restricted caloric intake, in line with our hypothesis. For the general manipulation, no group differences were found on caloric intake, which is surprising given earlier results (Daniel et al., 2015, 2013b). It was however suggested by Daniel et al. (2015) that participants in their study may have had food-specific images come to mind, by associating positive future images with food. Hence, their general manipulation could be more closely alike to our food-specific manipulation. Importantly, our sample of participants was different to the sample of Daniel et al. (2013b, 2015), where results were found for overweight/obese women and children high in dietary restraint. Our sample consisted of female students who were not necessarily motivated to restrict their caloric intake, which could make the possibility to restrict intake of snacks and show restraint seen as irrelevant. Earlier results show that the effect of episodic thinking is related to the vividness of the imagined events: the more vivid the imagery, the greater the reduction in discount rate (Peters \& Büchel, 2010). Vividness of imagery was possibly not equal between conditions in this earlier studies (Daniel et al., 2015, 2013b). As all images were rated as equal in vividness, realism, difficulty and details, the current study provided a strong control by generating episodic past events.

As stated in the introduction; we hypothesized that by changing discount rate, caloric intake would also be altered by making less impulsive food choices. However, as no association was observed 
Table 1

Means and standard deviations of participant characteristics per condition.

\begin{tabular}{|c|c|c|c|c|}
\hline & EPT-general $(n=24)$ & EFT-general $(n=23)$ & EPT-food $(n=23)$ & EFT-food $(\mathrm{n}=24)$ \\
\hline Age & $20.21(2.55)$ & $20.17(1.47)$ & $20.41(1.65)$ & $20.79(1.86)$ \\
\hline BMI & $22.16(2.47)$ & $22.51(3.84)$ & $22.58(2.82)$ & $22.51(2.94)$ \\
\hline Restraint & $11.96(4.15)$ & $12.57(4.57)$ & $12.48(5.36)$ & $12.71(3.84)$ \\
\hline CFC-Immediate food & $24.88(5.86)$ & $25.35(5.90)$ & $24.39(7.23)$ & $24.96(4.69)$ \\
\hline CFC-Future food & $29.58(7.01)$ & $28.83(6.55)$ & $31.48(4.79)$ & $32.42(4.98)$ \\
\hline Hunger $^{\mathrm{a}}$ & $52.17(22.60)$ & $51.00(22.26)$ & $47.61(30.45)$ & $62.08(19.40)$ \\
\hline Taste rating of snacks ${ }^{a}$ & $68.18(19.93)$ & $62.64(13.73)$ & $72.10(15.13)$ & $61.13(26.39)$ \\
\hline
\end{tabular}

Note. EPT = Episodic Past Thinking. EFT = Episodic Future Thinking. BMI = Body Mass Index. CFC-food = Consideration of Future Consequences scale - Food version.

a Rated by participants on a $100 \mathrm{~mm}$ VAS-scale, ranging from not at all (0) to very much (100).

Table 2

Means and standard deviations for ratings of generated images per condition.

\begin{tabular}{|c|c|c|c|c|}
\hline & EPT-general $(\mathrm{N}=24)$ & EFT-general $(\mathrm{N}=23)$ & EPT-food $(\mathrm{N}=23)$ & EFT-food $(\mathrm{N}=24)$ \\
\hline Realism & $5.60(0.77)$ & $5.61(0.93)$ & $5.79(0.68)$ & $5.73(0.75)$ \\
\hline Details & $4.94(0.87)$ & $4.65(0.84)$ & $5.04(0.77)$ & $4.92(0.83)$ \\
\hline Vividness & $5.41(0.72)$ & $5.19(0.78)$ & $5.55(0.59)$ & $5.52(0.64)$ \\
\hline Difficulty & $2.91(1.09)$ & $3.00(1.18)$ & $2.96(1.08)$ & $3.10(1.47)$ \\
\hline Positivity & $5.46(0.92)$ & $5.34(0.93)$ & $5.95(0.60)$ & $5.98(0.76)$ \\
\hline Future-orientated & $2.91(1.25)$ & $5.46(0.80)$ & $2.71(1.40)$ & $5.01(1.20)$ \\
\hline
\end{tabular}

Note. Images were rated by participants on a 7 -point Likert scale $(1=$ not at all; $7=$ very much $)$. EPT $=$ Episodic Past Thinking. EFT $=$ Episodic Future Thinking.

between discount rate and caloric intake, it appears that this was not the mechanism underlying the effect of EFT on caloric intake. As choices where about money in the current discount task, this measure does not fully capture the real dilemma, choosing between palatable foods or future health outcomes. Though discount rate has been measured with food as a reinforcer before (Dassen et al., 2015; Odum \& Rainaud, 2003; Rasmussen, Lawyer, \& Reilly, 2010), these measures neither capture the dilemma, because by no discounting of the future in this delay discounting tasks, the future reward would be to receive even more of the (unhealthy) food. Future delay discounting tasks mirroring this dilemma more closely could possibly clarify this. Importantly, as the reinforcing value of food has been found to interact with delay discounting in predicting BMI (Appelhans et al., 2011; Epstein et al., 2014), including a measure of the reinforcing value of food in future studies would possibly contribute to a better understanding of the variation in food consumption. Reducing discount rate may only help to prevent or intervene on obesity in those who are high in food reinforcement. In addition, the snacks provided in the current study consisted of a sample of sweet snacks, yet savory snacks are often also energy dense (de Graaf, 2006). Though data was
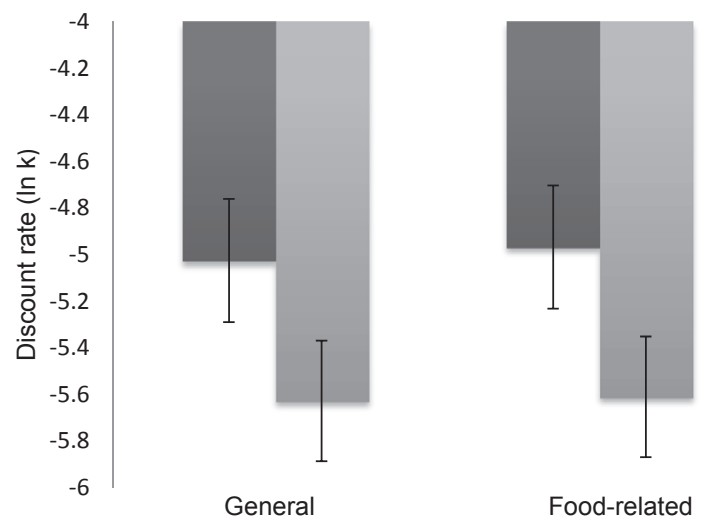

Fig. 1. Means of log-transformed k-value are plotted for delay discounting. Error bars represent the standard error of the mean. EPT = Episodic Past Thinking. EFT = Episodic Future Thinking. collected on how much the participants liked the snacks, no data were collected on snacking preferences. As a result, findings from the present study may not be representative for participants who prefer savory snacks over candy.

Results of Cheng, Shein, and Chiou (2012) showed that the effect of a future prime on discount rate and desirability of hedonic activities was mediated by time orientation. Time orientation was measured at a behavior-specific level in the current study. As no differences on the CFC-food subscales occurred between the EFT and EPT groups, time orientation seems not to be the underlying mechanism which caused changes in caloric intake. However, as CFC is considered to be a stable individual difference (Strathman et al., 1994; Toepoel, 2010), this questionnaire was probably not sensitive to pick up small changes in future orientation as a state. Thus, based on current results, the possibility that the manipulation activated a temporary focus on future health outcomes cannot be excluded. Interestingly, in the current study, for the food-specific manipulation we used a global instruction (think of an event which is related to food), which was not restricted to consider healthy or unhealthy consequences. As unhealthy eaters do not consider future health consequences (Dassen et al., 2015), tailoring the content to goals of weight loss and health benefits could turn

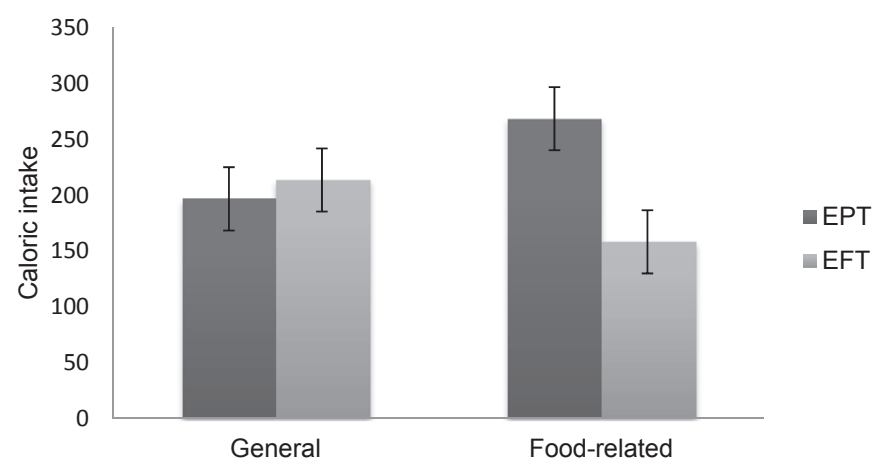

Fig. 2. Two-way analysis of covariance controlling for the effects of hunger and taste rating of snacks. Estimated Marginal Means are plotted for caloric intake. Error bars represent the standard error of the mean. EPT = Episodic Past Thinking. EFT = Episodic Future Thinking. 
out even more beneficial (Daniel et al., 2015). However, images should be realistic, as fantasizing has been shown to be not effective in changing behavior (Oettingen, 2012).

Importantly, based on current results, we cannot be sure whether food-related EFT reduced caloric intake, food-related EPT increased caloric intake, or both. Future research should therefore include a neutral control. In order to use EFT as an intervention, we would also like to encourage future studies to look into more detail how long time effects last, as any long term effects remain to be investigated. An interesting next step would be to investigate whether training individuals to engage in EFT would help to delay gratification in daily life.

In conclusion, the current findings indicate that impulsive behaviors can be controlled by envisioning the future vividly. Specifically, generating future images reduces impulsive decision making, whereas only the generating of food-related images influences caloric intake. Thus, it is beneficial to make the content of EFT food-related in order to change eating behavior. The underlying mechanism stays to be discovered as changes in discount rate did not directly result in more restricted caloric intake. Future studies should further explore the mechanisms underlying EFT and examine the longevity of effects on behavior. Current results propose EFT as a promising technique to change concern with immediate gratification to a more future-oriented outlook.

\section{Funding}

This project was funded by the Maastricht University Interfaculty Program 'Eatwell'

\section{References}

Appelhans, B. M., Waring, M. E., Schneider, K. L., Pagoto, S. L., DeBiasse, M. A., Whited, M. C., et al. (2012). Delay discounting and intake of ready-to-eat and away-from-home foods in overweight and obese women. Appetite, 59(2), 576-584.

Appelhans, B. M., Woolf, K., Pagoto, S. L., Schneider, K. L., Whited, M. C., \& Liebman, R. (2011). Inhibiting food reward: delay discounting, food reward sensitivity, and palatable food intake in overweight and obese women. Obesity, 19(11), 2175-2182.

Atance, C. M., \& O'Neill, D. K. (2001). Episodic future thinking. Trends in Cognitive Sciences, 5(12), 533-539.

Bar, M. (2010). Wait for the second marshmallow? Future-oriented thinking and delayed reward discounting in the brain. Neuron, 66(1), 4-5.

Bechara, A. (2005). Decision making, impulse control and loss of willpower to resist drugs: a neurocognitive perspective. Nature Neuroscience, 8(11), 1458-1463.

van Beek, J., Antonides, G., \& Handgraaf, M. J. (2013). Eat now, exercise later: the relation between consideration of immediate and future consequences and healthy behavior. Personality and Individual Differences, 54(6), 785-791.

Benoit, R. G., Gilbert, S. J., \& Burgess, P. W. (2011). A neural mechanism mediating the impact of episodic prospection on farsighted decisions. The Journal of Neuroscience, 31(18), 6771-6779.

Best, J. R., Theim, K. R., Gredysa, D. M., Stein, R. I., Welch, R. R., Saelens, B. E. et al. (2012). Behavioral economic predictors of overweight children's weight loss. Journal of Consulting and Clinical Psychology, 80(6), 1086.

Bickel, W. K., \& Marsch, L. A. (2001). Toward a behavioral economic understanding of drug dependence: delay discounting processes. Addiction, 96(1), 73-86.

Bickel, W. K., Miller, M. L., Yi, R., Kowal, B. P., Lindquist, D. M., \& Pitcock, J. A. (2007). Behavioral and neuroeconomics of drug addiction: competing neural systems and temporal discounting processes. Drug and Alcohol Dependence, 90, S85-S91.

Boyer, P. (2008). Evolutionary economics of mental time travel? Trends in Cognitive Sciences, 12(6), 219-224. http://dx.doi.org/10.1016/j.tics.2008.03.003.

Cheng, Y. Y., Shein, P. P., \& Chiou, W. B. (2012). Escaping the impulse to immediate gratification: the prospect concept promotes a future-oriented mindset, prompting an inclination towards delayed gratification. British Journal of Psychology, 103(1), 129-141.

D'Argembeau, A., Renaud, O., \& Van der Linden, M. (2011). Frequency, characteristics and functions of future-oriented thoughts in daily life. Applied Cognitive Psychology, 25(1), 96-103.

Daniel, T. O., Said, M., Stanton, C. M., \& Epstein, L. H. (2015). Episodic future thinking reduces delay discounting and energy intake in children. Eating Behaviors, 18 ,
$20-24$

Daniel, T. O., Stanton, C. M., \& Epstein, L. H. (2013a). The future is now: comparing the effect of episodic future thinking on impulsivity in lean and obese individuals. Appetite, 71, 120-125.

Daniel, T. O., Stanton, C. M., \& Epstein, L. H. (2013b). The future is now: reducing impulsivity and energy intake using episodic future thinking. Psychological Science, 2339-2342.

Dassen, F. C. M., Houben, K., \& Jansen, A. (2015). Time orientation and eating behavior: unhealthy eaters consider immediate consequences, while healthy eaters focus on future health. Appetite, 91, 13-19.

Drewnowski, A., \& Greenwood, M. (1983). Cream and sugar: human preferences for high-fat foods. Physiology \& Behavior, 30(4), 629-633.

Epstein, L. H., Jankowiak, N., Fletcher, K. D., Carr, K. A., Nederkoorn, C., Raynor, H. A et al. (2014). Women who are motivated to eat and discount the future are more obese. Obesity, 22(6), 1394-1399.

Finucane, M. M., Stevens, G. A., Cowan, M. J., Danaei, G., Lin, J. K., Paciorek, C. J., et al. (2011). National, regional, and global trends in body-mass index since 1980: systematic analysis of health examination surveys and epidemiological studies with 960 country-years and 9. 1 million participants. The Lancet, 377(9765), 557-567.

Flegal, K. M., Carroll, M. D., Kit, B. K., \& Ogden, C. L. (2012). Prevalence of obesity and trends in the distribution of body mass index among US adults, 1999-2010. Jama, 307(5), 491-497.

de Graaf, C. (2006). Effects of snacks on energy intake: an evolutionary perspective. Appetite, 47(1), 18-23.

Hall, P. A., \& Fong, G. T. (2007). Temporal self-regulation theory: a model for individual health behavior. Health Psychology Review, 1(1), 6-52.

Hall, P. A., Fong, G. T., \& Cheng, A. Y. (2012). Time perspective and weight management behaviors in newly diagnosed type 2 diabetes: a mediational analysis. Journal of Behavioral Medicine, 35(6), 569-580.

Herman, C. P., \& Polivy, J. P. (1980). Restrained eating. In A. J. Stunkard (Ed.), Obesity (pp. 208-225). Philadelphia: Saunders.

Hill, J. O., Melanson, E. L., \& Wyatt, H. T. (2000). Dietary fat intake and regulation of energy balance: implications for obesity. The Journal of Nutrition, 130(2), 284S-288S.

Jarmolowicz, D. P., Cherry, J. B. C., Reed, D. D., Bruce, J. M., Crespi, J. M., Lusk, J. L. et al. (2014). Robust relation between temporal discounting rates and body mass. Appetite, 78, 63-67.

Joireman, J., Shaffer, M. J., Balliet, D., \& Strathman, A. (2012). Promotion orientation explains why future-oriented people exercise and eat healthy: evidence from the two-factor consideration of future consequences-14 scale. Personality and Social Psychology Bulletin, 38(10), 1272-1287.

Kaplan, B. A., Lemley, S. M., Reed, D. D., \& Jarmolowicz, D. P. (2014). 21- and 27-Item monetary choice questionnaire automated scorers" [software]. Center for Applied Neuroeconomics, University of Kansas.

Kirby, K. N. (2009). One-year temporal stability of delay-discount rates. Psychonomic Bulletin \& Review, 16(3), 457-462.

Kirby, K. N., Petry, N. M., \& Bickel, W. K. (1999). Heroin addicts have higher discount rates for delayed rewards than non-drug-using controls. Journal of Experimental Psychology: General, 128(1), 78-87.

Koffarnus, M. N., Jarmolowicz, D. P., Mueller, E. T., \& Bickel, W. K. (2013). Changing delay discounting in the light of the competing neurobehavioral decision systems theory: a review. Journal of the Experimental Analysis of Behavior, 99(1), 32-57.

Lin, H., \& Epstein, L. H. (2014). Living in the moment: effects of time perspective and emotional valence of episodic thinking on delay discounting. Behavioral Neuroscience, 128(1), 12-17.

Odum, A. L., \& Rainaud, C. P. (2003). Discounting of delayed hypothetical money, alcohol, and food. Behavioural Processes, 64(3), 305-313.

Oettingen, G. (2012). Future thought and behaviour change. European Review of Social Psychology, 23(1), 1-63.

Peters, J., \& Büchel, C. (2010). Episodic future thinking reduces reward delay discounting through an enhancement of prefrontal-mediotemporal interactions. Neuron, 66(1), 138-148.

Rasmussen, E. B., Lawyer, S. R. \& Reilly, W. (2010). Percent body fat is related to delay and probability discounting for food in humans. Behavioural Processes, 83(1), 23-30

Schacter, D. L., Addis, D. R., \& Buckner, R. L. (2008). Episodic simulation of future events. Annals of the New York Academy of Sciences, 1124(1), 39-60.

Strathman, A., Gleicher, F., Boninger, D. S., \& Edwards, C. S. (1994). The consideration of future consequences: weighing immediate and distant outcomes of behavior: Journal of Personality and Social Psychology, 66(4), 742-752.

Toepoel, V. (2010). Is consideration of future consequences a changeable construct? Personality and Individual Differences, 48(8), 951-956.

Volkow, N. D., Wang, G.-J., \& Baler, R. D. (2011). Reward, dopamine and the control of food intake: implications for obesity. Trends in Cognitive Sciences, 15(1) $37-46$.

Weller, R. E., Cook, E. W., III, Avsar, K. B., \& Cox, J. E. (2008). Obese women show greater delay discounting than healthy-weight women. Appetite, 51(3), 563-569. 